\title{
EVALUASI PROSES PEMBERIAN FEEDBACK DI TUTORIAL PROBLEM-BASED LEARNING DI FAKULTAS KEDOKTERAN
}

\author{
Tezar Samekto Darungan*, Gandes Retno Rahayu**, Mora Claramita** \\ * Fakultas Kedokteran Universitas Islam Sumatera Utara \\ ** Fakultas Kedokteran Universitas Gadjah Mada
}

\begin{abstract}
Background: Feedback constitutes one of the important components in student Since feedback is not solely limited to student assignments, it can also be given during student learning, including tutorials. Therefore, the institution should pay particular attention to the process of feedback provision one of which is through evaluations on the process of providing feedback in tutorials. This study aimed to evaluate the process of providing feedback on the Problem-Based Learning tutorials in the Faculty of Medicine, Universitas Islam Sumatera Utara.
\end{abstract}

Method: This study used mixed methods with a quantitative method performed first, followed by a qualitative method with a phenomenology approach. The subjects were the undergraduate medical students of the class of 2012 and tutors of the Problem-Based Learning tutorials. The quantitative data analysis was done by the descriptive analysis while the qualitative data analysis was done through verbatim analysis, coding, categorization and conclusion.

Results: The students had received feedback but not routinely. Both the students and the tutors had perceived that feedback was important and gave them many benefits. In practice, feedback was given on the basis of tutors' direct observation results. Action plan was often given but rarely involved discussion. Self-assessment/ reflection was also not a matter of routine and the tutors did not know that it was part of the feedback. The contents of feedback were more often in the form of general comments. Feedback was often communicated in one direction. The students' response to feedback varied. In giving and receiving feedback, the students, the tutors, the tutorial activities and the content of the feedback itself could influence one another. The students had preferences so feedback can be more easily accepted and they focused on the structural aspects of feedback (the frequency of giving feedback, the detail and spesific feedback, two way communication in giving feedback and the feedback target). Tutors expected more trainings in giving feedback provided by institution to tutors and students.

Conclusion: Despite its valuable benefits, tutorial feedback in the Faculty of Medicine, Universitas Islam Sumatera Utara,is still not in accordance with the principle of providing feedback and many factors have affected this condition.

Keywords: evaluation, feedback, tutorials

\begin{abstract}
ABSTRAK
Latar belakang: Feedback merupakan salah satu komponen penting dalam pembelajaran termasuk dalam tutorial. Institusi harus memberi perhatian khusus terhadap proses pemberian feedback untuk meningkatkan kualitas tutorial. Evaluasi terhadap proses pemberian feedback di tutorial penting untuk dilakukan. Penelitian ini bertujuan untuk mengevaluasi proses pemberian feedback di tutorial Problem-Based Learning di Fakultas Kedokteran Universitas Islam Sumatera Utara
\end{abstract}

korespondensi: darungantezarsamekto@gmail.com 
Metode: penelitian ini menggunakan metode campuran (mixed methods) dengan metode kuantitatif dilanjutkan dengan metode kualitatif dengan pendekatan phenomenology. Subjek penelitian adalah mahasiswa angkatan 2012 dan tutor. Analisa data kuantitatif dilakukan dengan analisa deskriptif. Analisa data kualitatif dilakukan melalui analisis verbatim, koding, kategorisasi dan penarikan kesimpulan

Hasil: mahasiswa pernah menerima feedback namun tidak rutin. Mahasiswa dan tutor merasa bahwa feedback itu penting dan memiliki banyak manfaat. Dalam praktiknya, feedback diberikan atas dasar hasil observasi langsung tutor. Action plan sering diberikan namun jarang melibatkan diskusi. Self-assessment/refleksi juga bukan sebuah hal rutin dan tutor tidak tahu kalau itu merupakan bagian dari feedback. Isi feedback lebih sering berupa komentar umum. Feedback lebih sering dikomunikasikan dalam bentuk satu arah. Respons mahasiswa bervariasi dalam menanggapi feedback. Dalam memberi dan menerima feedback, mahasiswa, tutor, kegiatan tutorial dan isi feedback itu sendiri dapat mempengaruhi. Mahasiswa memiliki preferensi feedback yang berfokus pada aspek struktural feedback (frekuensi pemberian feedback, isi feedback yang detail dan spesifik, komunikasi dua arah dalam pemberian feedback dan sasaran feedback). Mahasiswa memiliki preferensi feedback yang berfokus pada aspek struktural feedback (frekuensi pemberian feedback, isi feedback yang detail dan spesifik, komunikasi dua arah dalam pemberian feedback dan sasaran feedback). Tutor lebih mengharapkan institusi yang kembali memberikan sosialisasi mengenai pemberian feedback yang baik.

Kesimpulan: walaupun feedback dirasa perlu dan memiliki banyak manfaat, feedback di tutorial Fakultas Kedokteran Universitas Islam Sumatera Utara masih belum sesuai dengan prinsip pemberian feedback. Banyak faktor yang mempengaruhi feedback yang masih belum sesuai dengan prinsip pemberian feedback.

Kata kunci: evaluasi, feedback, tutorial

\section{PENDAHULUAN}

Feedback dapat didefinisikan sebagai informasi yang mendeskripsikan performa mahasiswa dalam sebuah tugas atau aktivitas yang diberikan yang bertujuan sebagai panduan untuk tugas dan aktivitas yang sama di masa yang akan datang., ${ }^{1,2}$ Feedback diberikan dalam sebuah bentuk komunikasi dua arah yang sifatnya tidak menghakimi (non-judgemental) dengan tujuan untuk menyediakan sebuah informasi tentang suatu kualitas suatu pekerjaan untuk meningkatkan kualitas pekerjaan seseorang. ${ }^{3}$ Feedback tidak hanya terbatas pada hasil tugas yang telah dikerjakan mahasiswa, namun dapat juga diberikan pada proses pembelajaran mahasiswa seperti kinerja mahasiswa di laboratorium termasuk dalam proses tutorial. Feedback sering disebut sebagai the heart of medical education. ${ }^{4} \mathrm{Hal}$ ini cukup beralasan karena feedback menjadi inti dari pengalaman belajar mahasisa dan memotivasi serta mendorong pembelajar melalui transisi awal dan transisi di sepanjang jenjang pendidikan mereka. ${ }^{5}$ Feedback memiliki banyak tujuan termasuk meningkatkan pencapaian, pengembangan pemahaman dan kemampuan pembelajar dan dapat memotivasi mahasiswa dengan cara memacu dan mengenali usaha mereka dalam proses pembelajaran. ${ }^{6}$

Feedback dapat menjadi monitor dari proses selfregulating learning seorang mahasiswa. ${ }^{7}$ Feedback harus dapat menutup celah antara antara performa yang diharapkan dengan performa yang dilakukan pembelajar saat ini dengan memberi gambaran ke mahasiswa akan tujuan yang harus dicapai, pencapaian saat ini dan cara mencapai tujuan yang dicapai. ${ }^{8}$ Agar feedback dapat mencapai manfaatnya maka dalam pemberiannya, ada beberapa prinsip yang harus dipahami. ${ }^{1}$ Mulai dari persiapan pemberian feedback, hingga aspek struktural seperti waktu dan frekuensi pemberian, cara penyampaian (komunikasi) dan isi feedback itu sendiri. ${ }^{8-10}$ Sebagai panduan bagi pemberi feedback, maka dari prinsip-prinsip pemberian feedback tersebut dikembangkanlah beberapa model pemberian feedback seperti model sandwich, ${ }^{10}$ model SETGO, ${ }^{11,12}$ model TELL, ${ }^{3}$ model Pendleton, ${ }^{11,12}$ ALOBA, ${ }^{11,12}$ dan model-model lainnya. 
Dalam tutorial sebuah grup mahasiswa akan membahas sebuah masalah dan dari masalah tersebut mereka akan berkolaborasi untuk menganalisa, menimbang kemungkinan-kemungkinan pemecahan masalah untuk memperoleh pengetahuan yang lebih banyak, maju, dalam dan luas. ${ }^{13}$ Untuk memfasilitasi kegiatan diskusi mahasiswa dalam tutorial, sebuah grup didampingi oleh seorang tutor. Dalam tugasnya sebagai fasilitator, tutor juga bertugas memberi feedback. Feedback dalam tutorial menjadi sebuah bentuk asesmen formatif terhadap performa mahasiswa. ${ }^{14} \mathrm{Hal}$-hal yang dapat menjadi perhatian tutor dalam pemberian feedback dalam tutorial adalah kemampuan problem-solving, kemampuan self-directed learning, kontribusi terhadap kerja tim, kemampuan berkomunikasi, komitmen dan pengetahuan medis. ${ }^{15}$ Selain tutor sebagai pemberi feedback, mahasiswa juga memiliki andil agar feedback dapat efektif. Mahasiswa sebaiknya mengetahui poinpoin yang menjadi penilaian tutor dalam tutorial dan kemudian mahasiswa mengidentifikasi kekuatan dan kelemahan dari tiap poin-poin tersebut. ${ }^{10,15}$ Mahasiswa juga sebaiknya menghargai feedback sebagai sesuatu yang penting dalam pencapaian tujuan belajar. ${ }^{6}$ Tanpa adanya komentar tentang kemajuan mereka dalam proses belajar, mahasiswa tak sadar kalau mereka dalam bahaya besar. ${ }^{16}$

Dalam pemberian feedback, ternyata banyak yang menyatakan kalau feedback belum diberikan secara efektif dan mahasiswa yang belum merasa mendapatkan feedback yang cukup. ${ }^{17,18}$ Banyak faktor yang menyebabkan mahasiswa tak dapat menggunakan feedback yang diberikan. ${ }^{19-21}$

Fakultas Kedokteran Universitas Islam Sumatera Utara telah menerapkan Kurikulum Berbasis Kompetensi dan menjadikan tutorial sebagai salah satu metode pembelajaran sejak 2007. Sebagai sebuah salah satu fitur penting dalam tutorial, aspek kualitas dalam pemberian feedback harus diperhatikan. Institusi diharapkan juga memperhatikan proses pemberian feedback dalam tutorial agar tujuan tutorial yang diharapkan dapat tercapai. Mulai dari pelaksanaan tutorial, belum pernah dilakukan sebuah proses evaluasi khususnya terhadap proses pemberian feedback. Adapun evaluasi yang telah dijalankan, tidak pernah ditindaklanjuti oleh pihak institusi, sehingga bisa dikatakan bahwa proses evaluasi yang ada selama ini tidak berjalan sebagaimana mestinya. Dan proses evaluasi yang ada hanya menyoroti kemampuan tutor, namun tidak melihat struktur feedback itu sendiri.

Sebuah evaluasi proses termasuk dalam evaluasi formatif yang bertujuan untuk memperbaiki sebuah program kebijakan dan sekelompok staf dan sebuah evaluasi proses tidak melihat bagaimana hasil dari proses yang dievaluasi. ${ }^{22}$ Jika dihubungkan dengan penelitian yang dilakukan penulis, dalam sebuah evaluasi proses, ada 3 komponen kunci yang menjadi perhatian. ${ }^{23}$ Komponen pertama adalah bagaimana implementasi dari proses pemberian feedback tersebut, sudahkah seperti yang diharapkan atau belum. Komponen kedua adalah menyoroti respons mahasiswa dalam menerima feedback dan komponen terakhir adalah komponen eksternal yang dapat mengintervensi proses pemberian feedback tersebut.

Tujuan penelitian ini adalah penulis ingin melihat pemahaman mahasiswa dan tutor terhadap feedback termasuk manfaat dari feedback itu sendiri di sebuah kegiatan tutorial, melihat apakah feedback yang diberikan dalam tutorial sesuai dengan prinsip pemberian feedback yang baik, respons mahasiswa terhadap feedback yang diberikan tutor, faktor-faktor yang mempengaruhi pemberian dan penerimaan feedback serta penulis juga ingin mengetahui preferensi feedback yang diinginkan mahasiswa dan tutor dalam tutorial.

\section{METODE}

Penelitian ini dilakukan di Fakultas Kedokteran Universitas Islam Sumatera Utara Jalan Sisingamangaraja no. 2A pada 55 mahasiswa semester 7 dan 5 tutor yang terpilih dari metode simple random sampling grup tutorial dengan menggunakan pendekatan mixed methods. Pendekatan kuantitatif dilakukan untuk menjawab pertanyaan penelitian kesesuaian tahapan pemberian feedback yang terjadi di Fakultas Kedokteran Universitas Islam Sumatera Utara dengan prinsip pemberian feedback. Kuesioner ini terdiri dari 5 item pernyataan tahapan pemberian feedback untuk performa grup dan 6 item pernyataan untuk performa individu. Seluruh item telah dinyatakan valid (Pearson Correlation $>0,35$ ) dan 
reliabilitas (Cronbach's alpha >0,7). Kuesioner diuji dengan analisis deskriptif. Hasil analisa deskriptif dijadikan sebagai bahan Focus Group Discussion mahasiswa dan wawancara mendalam dengan tutor.

Focus Group Discussion mahasiswa dan wawancara tutor sebagai bentuk triangulasi sumber adalah metode pengumpulan data untuk pendekatan kualitatif jenis phenomenology. ${ }^{22,24}$ Kedua metode ini digunakan untuk menjawab pertanyaan penelitian selain pertanyaan penelitian yang dijawab oleh kuesioner. Focus Group Discussion dilakukan masing-masing 2 kali untuk 3 grup tutorial dan 1 kali untuk 2 grup tutorial lainnya. Wawancara tutor dilakukan 2 kali masing-masing untuk 4 tutor dan 1 kali untuk 1 tutor lainnya. Keseluruhan proses diskusi dan wawancara direkam dan hasil rekaman audio ditranskrip untuk menjadi verbatim. Verbatim kemudian dibaca berulang-ulang untuk mendapatkan pola-pola penting. Dari pola-pola penting tersebut kemudian dicari kategori-kategori untuk menjawab pertanyaan penelitian. ${ }^{22}$ Proses mencari pola dan kategorisasi ini dilakukan bersama dengan asisten peneliti.

Penelitian evaluasi proses ini tidak mecakup observasi langsung proses tutorial karena keterbatasan waktu. Proses mengumpulkan mahasiswa dan mampu memancing mahasiswa untuk dapat berpendapat dengan aktif dirasa cukup menyulitkan. Penulis menyarankan untuk melakukan simulasi diskusi dan wawancara sebelum melakukan dengan informan sebenarnya untuk melatih kemampuan bertanya dan manjadi fasilitator diskusi.

\section{HASIL DAN PEMBAHASAN}

\section{Pemahaman mahasiswa dan tutor akan feedback}

Penelitian ini menemukan bahwa mahasiswa dan tutor, merasa bahwa feedback, adalah sesuatu yang penting di tutorial dan memberi banyak manfaat bagi pembelajaran mahasiswa.

"dalam setiap SGD itu saya rasa, saya memang harus selalu memberikan feedback. jadi saya rasa saya tidak merasa terbebani. Karena saya rasa feedback itu penting sih demi kelancaran SGD tersebut (4.W2T2)
Feedback banyak didefinisikan oleh mahasiswa dan tutor sebagai bentuk penilaian secara kualitatif terhadap pendapat dilontarkan mahasiswa dalam tutorial dan atau performa mahasiswa dalam diskusi dan atau profesionalisme mahasiswa dan atau pemahaman materi diskusi mahasiswa.

"kita mengemukakan suatu pendapat, jadi tutor itu akan memberikan penilaian terhadap pendapat yang kita ungkapkan. Misalnya kita ungkapkan sebuah teori, tutor akan beri penilaian, tapi tidak cuma sekedar itu, tapi juga ngasi tambahan atau ilmu lain yang berhubungan dengan topik yang disampaikan " (2.D1K1)

Feedback juga sering dipahami sebagai petunjuk dan atau arahan dan atau pancingan dari tutor agar mahasiswa mendapatkan hal yang benar dari kesalahan. Petunjuk/arahan/pancingan tersebut dianggap sebagai tambahan informasi. Tambahan informasi ini juga sering disalahartikan dalam wujud kuliah mini.

"ketika sang mahasiswa ini memberi pendapatnya, tutor ini berusaha mengarahkan agar pendapat yang diberikan mahasiswa sesuai dengan konteks yang dituntut dalam pembelajar, sehingga pada akhirnya tidak terjadi persepsi salah" (8.D1K4)

"Terkadang memang kuliah mini, kayak kami rasa dia sedang memberi feedback" (19.D1K5)

\section{Feedback dalam tutorial Fakultas Kedokteran Universitas Islam Sumatera Utara}

Untuk melihat praktik pemberian feedback yang selama ini terjadi di tutorial Fakultas Kedokteran Universitas Islam Sumatera Utara, penulis juga menggunakan kuesioner untuk melihat apakah tahapan pemberian feedback dimulai dengan sebuah sesi self-assessment baik untuk performa terkait grup maupun individu. 
Tabel 1. Persepsi mahasiswa mengenai tahapan pemberian feedback di tutorial terkait performa grup

\begin{tabular}{|c|c|c|c|c|c|c|c|}
\hline No & Persepsi Mahasiswa & $\begin{array}{l}\text { Tidak } \\
\text { Pernah } \\
\text { (1) }\end{array}$ & $\begin{array}{l}\text { Jarang } \\
\text { (2) }\end{array}$ & $\begin{array}{l}\text { Kadang- } \\
\text { kadang } \\
\text { (3) }\end{array}$ & $\begin{array}{l}\text { Sering } \\
(4)\end{array}$ & $\begin{array}{l}\text { Selalu } \\
\text { (5) }\end{array}$ & $\begin{array}{l}\text { Mean } \\
(\mathrm{n}=55)\end{array}$ \\
\hline 1. & $\begin{array}{l}\text { Tutor meminta salah satu mahasiwa } \\
\text { untuk menilai diri sendiri (self- } \\
\text { assessment) terhadap hal-hal yang } \\
\text { memerlukan perbaikan dalam grup } \\
\text { di kegiatan tutorial }\end{array}$ & $58 \%$ & $29,1 \%$ & $12,7 \%$ & - & - & 1,55 \\
\hline 2. & $\begin{array}{l}\text { Tutor mengidentifikasi tujuan yang } \\
\text { harus dicapai grup dalam tutorial }\end{array}$ & - & $12,7 \%$ & $41,8 \%$ & $36,4 \%$ & $9,1 \%$ & 3,42 \\
\hline 3. & $\begin{array}{l}\text { Tutor memuji pencapaian } \\
\text { mahasiswa dalam grup di dalam } \\
\text { tutorial }\end{array}$ & $7,3 \%$ & $25,5 \%$ & $50,9 \%$ & $16,4 \%$ & - & 2,76 \\
\hline 4. & $\begin{array}{l}\text { Tutor mengarahkan, menyarankan } \\
\text { serta mendiskusikan dengan grup } \\
\text { hal-hal yang dapat dilakukan untuk } \\
\text { mencapai tujuan }\end{array}$ & - & $7,3 \%$ & $40 \%$ & $47,3 \%$ & $5,5 \%$ & 3,51 \\
\hline 5. & $\begin{array}{l}\text { Tutor menyimpulkan hal-hal yang } \\
\text { dapat dilakukan oleh grup untuk } \\
\text { mencapai tujuan dan membuat } \\
\text { action plan }\end{array}$ & $5,5 \%$ & $18,2 \%$ & $54,5 \%$ & $20 \%$ & $1,8 \%$ & 2,95 \\
\hline
\end{tabular}

Tabel di atas menunjukkan bahwa untuk tahapan self-assessment/refleksi, 32 mahasiswa dari 55 responden (58\% dengan nilai rata-rata 1,55 ) mahasiswa menyatakan bahwa hal tersebut tidak pernah dilakukan oleh tutor mereka. Tahapan feedback yang lebih sering diterima mahasiswa adalah tahapan feedback memberikan komentar apa yang harus dicapai (walaupun masih ada di frekuensi kadang-kadang sebanyak 41,8 \% dengan rata-rata $3,42)$. Tahapan tutor memberikan arahan akan apa yang harus dilakukan mahasiswa dinilai mahasiswa sering dilakukan oleh tutor (47,3\% dengan rata-rata 3,51). Tahapan tutor memuji pencapaian mahasiswa dinyatakan kadang-kadang diberikan oleh tutor $(50,9 \%$ dengan rata-rata 2,76). Action plan juga dinilai paling besar untuk porsi kadang-kadang sebagai tahapan pemberian feedback yang diberikan tutor yaitu 54,5\% mahasiswa dari 55 mahasiswa informan. 
Tabel 2. Persepsi mahasiswa mengenai tahapan pemberian feedback di tutorial terkait performa individu

\begin{tabular}{|c|c|c|c|c|c|c|c|}
\hline No & Tahapan pemberian feedback & $\begin{array}{l}\text { Tidak } \\
\text { pernah } \\
\quad(1)\end{array}$ & $\begin{array}{l}\text { Jarang } \\
\text { (2) }\end{array}$ & $\begin{array}{l}\text { Kadang } \\
\text { kadang } \\
\text { (3) }\end{array}$ & $\begin{array}{l}\text { Sering } \\
\text { (4) }\end{array}$ & $\begin{array}{c}\text { Selalu } \\
\text { (5) }\end{array}$ & $\begin{array}{c}\text { Mean } \\
(\mathrm{n}=55)\end{array}$ \\
\hline 1 & $\begin{array}{l}\text { Tutor menanyakan apa yang sudah } \\
\text { benar dikerjakan oleh mahasiswa } \\
\text { yang bersangkutan }\end{array}$ & $56,4 \%$ & $36,4 \%$ & $7,3 \%$ & - & - & 1,51 \\
\hline 2. & $\begin{array}{l}\text { Tutor menanyakan mahasiswa yang } \\
\text { lain dalam grup apa yang mereka } \\
\text { pikir telah dilakukan dengan baik } \\
\text { oleh mahasiswa yang bersangkutan }\end{array}$ & $60 \%$ & $25,5 \%$ & $12,7 \%$ & $1,8 \%$ & - & 1,56 \\
\hline 3. & $\begin{array}{l}\text { Tutor menanyakan kepada mahasiswa } \\
\text { yang bersangkutan apa hal-hal yang } \\
\text { belum ia kerjakan dengan benar }\end{array}$ & $49,1 \%$ & $29,1 \%$ & $16,4 \%$ & $3,6 \%$ & $1,8 \%$ & 1,8 \\
\hline 4. & $\begin{array}{l}\text { Tutor menanyakan kepada mahasiswa } \\
\text { bersangkutan bagaimana cara agar } \\
\text { performanya dalam tutorial menjadi } \\
\text { lebih baik }\end{array}$ & $40 \%$ & $25,5 \%$ & $32,7 \%$ & $1,8 \%$ & - & 1,96 \\
\hline 5. & $\begin{array}{l}\text { Tutor menanyakan kepada mahasiswa } \\
\text { yang lain dalam grup apa yang mereka } \\
\text { pikir belum dikerjakan dengan benar } \\
\text { oleh mahsiswa yang bersangkutan. }\end{array}$ & $50,9 \%$ & $30,9 \%$ & $16,4 \%$ & $1,8 \%$ & - & 1,69 \\
\hline 6 & $\begin{array}{l}\text { Tutor mengumpulkan pendapat dari } \\
\text { mahasiswa yang lain dalam grup } \\
\text { bagaimana cara yang dapat dilakukan } \\
\text { oleh mahasiswa bersangkutan agar } \\
\text { menjadi lebih baik }\end{array}$ & $50,9 \%$ & $36,4 \%$ & $12,7 \%$ & - & - & 1,6 \\
\hline
\end{tabular}

Dari tabel di atas, seperti halnya self-assessment/ refleksi pada grup, self-assessment/refleksi untuk individu (pernyataan nomor 1 dan 3) juga dinilai mahasiswa tidak pernah dilakukan oleh tutor mereka $(56,4 \%$ dengan rata-rata 1,51$)$. Selain itu, pernyataan nomor 2 dan 5 yang mencerminkan peer-feedback juga seluruhnya dinilai tidak pernah dilakukan oleh tutor mereka di tutorial dengan masing-masing memiliki persentase di porsi tidak pernah sebesar $60 \%$ (dengan rata-rata 1,96) dan 50,9\% (dengan rata-rata 1,69). Pernyataan nomor $4 \& 6$ yang menggambarkan penentuan action plan dengan mendiskusikannya dengan rekan se-grup mahasiswa dan dengan mahasiswa sendiri juga dinilai tidak pernah dilaukan oleh tutor mereka dengan masing-masing persentase $40 \%$ (dengan rata-rata 1,96 ) dan 50,9\% (dengan rata-rata 1,6$)$.

Untuk melihat kesesuaian prakitk pemberian feedback di tutorial Fakultas Kedokteran Universitas Islam Sumatera Utara dengan prinsip pemberian feedback yang baik dapat dilihat di tabel 3 dan tabel 4. Tabel 3 berisi contoh kutipan mahasiswa dan tutor yang menunjukkan praktik pemberian feedback yang sesuai dengan prinsip pemberian feedback dan tabel 4 berisi contoh kutipan mahasiswa dan tutor yang menunjukkan praktik pemberian feedback yang tidak sesuai dengan prinsip pemberian feedback yang baik. 
Tabel 3. Contoh pemberian feedback di tutorial yang sesuai dengan prinsip pemberian feedback yang baik

\begin{tabular}{|c|c|c|c|c|}
\hline & No. & $\begin{array}{l}\text { PEMBERIAN } \\
\text { FEEDBACK DI } \\
\text { TUTORIAL }\end{array}$ & MAHASISWA & TUTOR \\
\hline \multirow[t]{2}{*}{$\begin{array}{l}\text { Pemberian feedback } \\
\text { di tutorial Fakultas } \\
\text { Kedokteran } \\
\text { Universitas Islam } \\
\text { Sumatera Utara yang } \\
\text { sesuai dengan prinsip } \\
\text { pemberian feedback } \\
\text { yang baik }\end{array}$} & 1. & $\begin{array}{l}\text { Feedback berdasarkan } \\
\text { hasil observasi langsung } \\
\text { tutor }\end{array}$ & $\begin{array}{l}\text { "misalnya saat } \\
\text { kita presentasi, } \\
\text { ada gaya, mimik } \\
\text { saat presentasi.. } \\
\text { jadi feedback } \\
\text { dari dosen itu, ya } \\
\text { memperhatikannya } \\
\text { saat kita presentasi” } \\
\text { (23.D1K5) }\end{array}$ & $\begin{array}{l}\text { "memantau kegiatan } \\
\text { tutorial itu bagaimana } \\
\text { dan mungkin } \\
\text { memberikan komentar } \\
\text { setelah itu bagaimana } \\
\text { misalnya presentasi } \\
\text { mereka, slide presentasi } \\
\text { mereka,pemahamannya... } \\
\text { ya mungkin sekitar itu" } \\
\text { (8.W1T1) }\end{array}$ \\
\hline & 2. & $\begin{array}{l}\text { Feedback diberikan } \\
\text { pada hal-hal yang } \\
\text { dapat diubah termasuk } \\
\text { komentar/arahan/ } \\
\text { action plan terhadap } \\
\text { pendapat, performa dan } \\
\text { profesionalisme }\end{array}$ & $\begin{array}{l}\text { "salah satu metode } \\
\text { berkomunikasi, } \\
\text { bagaimana cara } \\
\text { presentasi dan } \\
\text { bagaimana sikap } \\
\text { profesionalisme kita } \\
\text { sebagai mhswa" } \\
\text { (62.D1K4) }\end{array}$ & $\begin{array}{l}\text { "Karena saya } \\
\text { juga pernah ngasi } \\
\text { contoh sama mereka } \\
\text { bagaimana etika yang } \\
\text { mesti dilakukan sesama } \\
\text { teman sejawat atau } \\
\text { mungkin ke teman } \\
\text { sejawat yang lebih tua } \\
\text { atau sejawat yang lebih } \\
\text { muda." (20.W1T3) }\end{array}$ \\
\hline
\end{tabular}

\begin{tabular}{|c|}
\hline $\begin{array}{c}\text { Prinsip Pemberian } \\
\text { Feedback yang Baik }\end{array}$ \\
\hline \hline $\begin{array}{c}\text { Pemberian Feedback } \\
\text { di Fakultas Kedokteran } \\
\text { Universitas Islam Sumatera Utara }\end{array}$ \\
\hline \hline Pemberian Feedback \\
di Fakultas Kedokteran \\
Universitas Illam \\
Sumatera Utara \\
yang sesuai dengan Prinsip \\
Pemberian Feedback \\
yang Baik
\end{tabular}
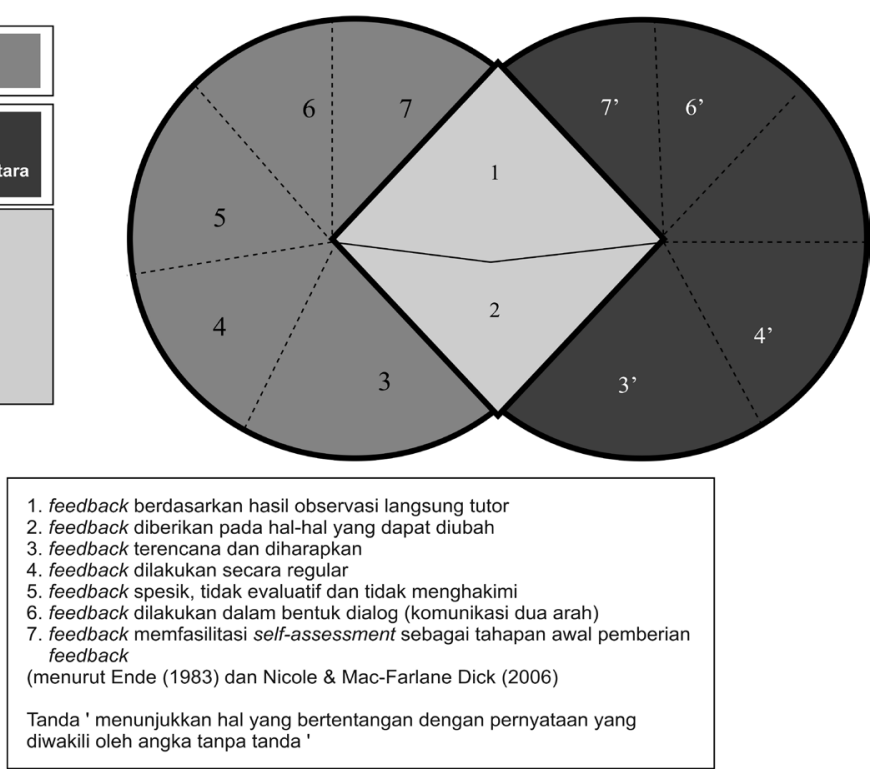

Gambar 1. Perbandingan prinsip pemberian feedback yang baik dengan pelaksanaan pemberian feedback di Fakultas Kedokteran Universitas Islam Sumatera Utara 
Tabel 4. Contoh pemberian feedback di tutorial yang belum sesuai dengan prinsip pemberian feedback yang baik

\begin{tabular}{|c|c|c|c|c|}
\hline & No & $\begin{array}{l}\text { PEMBERIAN } \\
\text { FEEDBACK DI } \\
\text { TUTORIAL }\end{array}$ & MAHASISWA & TUTOR \\
\hline \multirow[t]{5}{*}{$\begin{array}{l}\text { Pemberian feedback } \\
\text { di tutorial Fakultas } \\
\text { Kedokteran } \\
\text { Universitas Islam } \\
\text { Sumatera Utara } \\
\text { yang belum sesuai } \\
\text { dengan prinsip } \\
\text { pemberian feedback } \\
\text { yang baik }\end{array}$} & 1. & $\begin{array}{l}\text { Feedback tidak } \\
\text { diberikan regular }\end{array}$ & $\begin{array}{l}\text { "menurut saya, ga rutin. } \\
\text { Soalnya kadang ada tutor } \\
\text { yang cuek aja, jd berjalan } \\
\text { saja, dia ga ngasi feedback } \\
\text { dan itu hampir setiap } \\
\text { blok...jd saya rasa tutor itu } \\
\text { tidak rutin ngasi feedback" } \\
\text { (11.D1K5) }\end{array}$ & $\begin{array}{l}\text { "saya bilang rajin saya bingung. } \\
\text { Rata-rata saya memberikan } \\
\text { [feedback]. Tapi terkadang } \\
\text { ada kondisi ya saya tidak } \\
\text { memberikan feedback itu" } \\
\text { (6.W1T2) }\end{array}$ \\
\hline & 2. & $\begin{array}{l}\text { Feedback jarang } \\
\text { terencana }\end{array}$ & $\begin{array}{l}\text { "sejauh ini kalau tutor } \\
\text { ngasi feedback, tak ada } \\
\text { perjanjian di awal minggu } \\
\text { pertama dan tak ada } \\
\text { di } 10 \text { menit terakhir dia } \\
\text { [tutor] ngasi feedback juga } \\
\text { tidak." (22.D1K4) }\end{array}$ & $\begin{array}{l}\text { "kalau feedback mungkin ya } \\
\text { seiring berjalan tutorial sajA." } \\
\text { 20.W1T1 }\end{array}$ \\
\hline & 3. & $\begin{array}{l}\text { Feedback sering } \\
\text { tidak spesifik, } \\
\text { masih berupa } \\
\text { komentar umum } \\
\text { dan masih } \\
\text { menghakimi }\end{array}$ & $\begin{array}{l}\text { "yg paling sering...oke } \\
\text { grupnya bagus atau } \\
\text { LOnya tak tercapai ini” } \\
(52 . D 1 \mathrm{~K} 2)\end{array}$ & $\begin{array}{l}\text { "kalau saya pribadi, ya tidak } \\
\text { terlalu detail tapi mencoba } \\
\text { lebih baik. Kalau soal detail } \\
\text { mahasiswalah yang menilai } \\
\text { detail atau tidaknya"(30.W1T3) }\end{array}$ \\
\hline & 4. & $\begin{array}{l}\text { Feedback masih } \\
\text { sering berupa } \\
\text { komunikasi satu } \\
\text { arah }\end{array}$ & $\begin{array}{l}\text { "hari kedua itu kamu } \\
\text { kurangnya di sini, jd ntar } \\
\text { ditambahi ya" (70.D1K1) }\end{array}$ & $\begin{array}{l}\text { "nah di situlah saya suruh } \\
\text { dia yang menuliskan di white } \\
\text { boardnya itu tentang mapping } \\
\text { concept terkait dgn scenario" (46. } \\
\text { W1T2) }\end{array}$ \\
\hline & 5. & $\begin{array}{l}\text { Self-assessment } \\
\text { jarang dilakukan } \\
\text { sebagai bagian dari } \\
\text { feedback }\end{array}$ & $\begin{array}{l}\text { "ada beberapa tutor yg } \\
\text { ngasi feedback. dia nanya } \\
\text { sampai mana kemampuan } \\
\text { kalian, berapa jam kalian } \\
\text { belajar. Tentu saja kan } \\
\text { kita kan akan melihat lagi } \\
\text { ke diri kita." (31.D1K5) }\end{array}$ & $\begin{array}{l}\text { "Pokoknya selama ini yang saya } \\
\text { jalani ya seperti itu. Kalau } \\
\text { masalah meminta menilai diri } \\
\text { sendiri, memang tak pernah saya } \\
\text { kerjakan" (32.W1T2) }\end{array}$ \\
\hline
\end{tabular}




\section{Respons mahasiswa terhadap feedback dalam tutorial}

Dalam menanggapi feedback yang diberikan oleh tutor, mahasiswa memiliki respons yang beragam. Ada yang pasrah dengan feedback yang dibeirkan, ada pula yang membantah karena mahasiswa tidak menerima feedback yang diberikan oleh tutornya.

"paling cuma iya saja bang. biar cepat selesai diskusinya, satu lagi memang jawabannya tepat. Tapi ada juga segelintir mahasiwa yang betul-betul memang kalau diberi feedback tak sesuai dengan dia langsung dibantahnya, bahkan pernah itu lagi diskusi di SGD ada yang berdebat antara mahasiwa ama tutornya gara-gara feedback' (88.D1K1)

"Yang pertama saya pernah dapat kasus, memperhatikan, antusias tapi tak ada bertanya... yang kedua memperhatikan, sebagian antusias sebagian Cuma sekedarnya saja tapi bertanya, yang terakhir yang mendengarkan dan juga ada yang terkadang anggap sepele tutornya" (26.W2T3)

\section{Faktor-faktor yang mempengaruhi penerimaan dan pemberian feedback}

Ada beberapa faktor yang dapat mempengaruhi pemberian dan penerimaan feedback dalam tutorial yang teridentifikasi dalam penelitian ini. Faktor yang paling utama adalah tentu saja tutor sebagai pemberi feedback, namun mahasiswa turut juga mempengaruhi. Feedback yang tidak secara rutin diberikan oleh tutor dalam tutorial dengan berbagai alasan menyebabkan mahasiswa sering terpapar tutorial dengan feedback. Sebagai akibatnya beberapa mahasiswa akan resisten bila ada tutor yang memiliki kebiasaan memberi feedback. Gaya tutor yang juga berbeda dalam memfasilitasi tutorial juga menyebabkan beberapa mahasiswa menjadi inkonsisten dengan perubahan yang bisa saja sudah terjadi sebagai efek dari feedback tutor sebelumnya. Sebaliknya tutor pun dipengaruhi oleh mahasiswa dalam memberikan feedbacknya. Bila tutor sudah memberi feedback, namun tidak diindahkan oleh mahasiswa, maka ada kecenderungan tutor untuk enggan memberi feedback kembali. Efeknya mahasiswa kembali lagi terpapar dalam keadaan tanpa feedback. Selain faktor tutor dan mahasiswa, faktor tutorial dan isi feedback juga teridentifikasi dapat mempengaruhi pemberian dan penerimaan feedback oleh tutor.

\section{Preferensi isi feedback}

Isi feedback yang lebih mengeksplorasi kekurangan namun tetap memiliki porsi seimbang antara kelebihan dan kekurangan merupakan salah satu preferensi isi feedback yang diinginkan mahasiswa. Feedback juga diharapkan untuk lebih fokus ke arahan dan solusi serta ada mahasiswa yang menginginkan ancaman dan tugas yang menyertai feedback. Feedback yang dikaitkan dengan situasi nyata yang menggambarkan suasana kerja saat mahasiswa kelak menjadi dokter lebih disukai mahasiswa. Dan mahasiswa berharap agar feedback disesuaikan dengan angkatan mahasiswa.

Selain isi, mahasiswa juga menginginkan agar feedback diberikan secara interaktif (melibatkan diskusi) dengan sasaran feedback untuk tiap individu (walau ada yang menginginkan feedback diberikan untuk grup). Feedback yang diberikan dengan bahasa yang baik, tutor yang tidak menunjukkan superioritasnya dalam memberi feedback juga menjadi harapan mahasiswa.

Institusi juga diharapkan memberi perhatian lebih dengan memberi sosialisasi kepada tutor dan mahasiswa tentang feedback. Sosialisasi ini dapat berupa pelatihan ataupun pemberian materi feedback ke mahasiswa.

\section{Pembahasan}

Feedback adalah sesuatu yang disadari penting dan memberi manfaat oleh mahasiswa dan tutor Fakultas Kedokteran Universitas Islam Sumatera Utara. Feedback dapat dijadikan motivasi dan mengarahkan mahasiswa ke tujuan pembelajaran yang ingin dituju dalam sebuah sesi tutorial. Sesuai dengan yang dikatakan Butler \& Winne yang menyatakan bahwa feedback dapat mengarahkan dan memacu mahasiswa. ${ }^{25}$ Hattie \& Timperley menyatakan juga bahwa feedback dapat memberi gambaran ke mahasiswa bagaiamana sebuah tugas dikerjakan. ${ }^{8}$

Mahasiswa banyak menghubungkan feedback dengan ilmu pengetahuan. Seperti yang diutarakan Butler \& Winne, feedback dapat mengkonfirmasi pemahaman konsep,menambah pengetahuan, memperbaiki konsep yang salah dan feedback dapat merestrukrisasi skema atas konsep yang selama ini benar oleh 
mahasiswa. ${ }^{25}$ Feedback dalam khasanah pengetahuan ini dapat mencapai fungsinya bila mahasiswa sudah memiliki prior knowledge. ${ }^{8}$ Bila tidak, maka sebuah sesi feedback akan jatuh ke sesi kuliah atau pemberi feedback justru dianggap menjadi narasumber pengetahuan dan mahasiswa akan langsung meminta jawaban, bukan lagi meminta arahan atau petunjuk sebagai feedback untuk memperkaya khasanah pengetahuan yang sudah dimiliki mahasiswa. ${ }^{8,26}$

Feedback juga dirasa dapat dijadikan sarana refleksi. Eva \& Regehr menyatakan bahwa refleksi adalah strategi pembelajaran yang bertujuan membuat mahasiswa menyadari dengan sengaja mengeksplorasi dan mengelaborasi pemhaman mahasiswa akan suatu masalah. ${ }^{27}$ Dengan proses ini, diharapkan mahasiwa dapat membentuk struktur baru mengenai konsep, pengetahuan, keahlian dan nilai lain terhadap struktur yang ada ${ }^{4}$ dan membuka titik buta seorang mahasiswa yang diakibatkan mahasiswa tidak mengetahui sesuatu namun diketahui oleh tutor. ${ }^{28}$

Agar feedback dapat mencapai manfaat, maka tutor harus dapat diberikan dengan efektif. Salah satu faktor yang turut berperan adalah tutor, sebagai pemberi feedback. ${ }^{29}$ Dalam tugasnya, tutor harus mestimulasi elaborasi ide dan informasi, mengarahkan proses belajar, menstimulasi integrasi pengetahuan dan menstimulasi interaksi/kolaborasi mahasiswa dan mengintervensi di saat tepat. Tutor juga bukan menjadi ahli dari materi yang sedang didiskusikan, tutor tidak memberi kulaih dan tutor tidak mendominasi grup. ${ }^{30,31}$ Filosofi tutor yang tidak dipahami oleh tutor akan mengganggu jalannya tutorial, termasuk menghilangkan keberadaan pemberian feedback. ${ }^{32}$ Tutor juga harus menyadari bahwa karakteristik tutor yang baik tak hanya soal pengetahuan (baik pengetahuan medis maupun pengetahuan konsep Problem-Based Learning) dan keahlian memfasilitasi. Tutor juga harus memiliki sikap yang baik, karena bagaimanapun tutor adalah sebuah peran lain dari seorang guru yang juga menjadi role model yang baik. ${ }^{30,33}$

Dalam pemberiannya, feedback adalah sebuah dialog. Tutor harus mampu mendorong mahasiswa masuk ke dalam dialog feedback dan membentuk keterikatan dengan feedback yang diberikan oleh tutor. Kepercayan dan kredibilitas tutor turut mempengaruhi penggunaaan feedback oleh mahasiswa. ${ }^{34}$
Agar dialogfeedback dapat terbentuk, maka tutor harus memperhatikan aspek struktrual feedback. ${ }^{35}$ Dalam hal waktu pemberian feedback, feedback dapat saja diberikan secara formal (dalam sebuah sesi) ataupun informal (langsung diberikan). ${ }^{20}$ Terlepas dari adanya sesi atau tidak, feedback harus diantisipasi mahasiswa dengan memberitahu mahasiswa bahwa tutor akan memberi feedback. ${ }^{36}$ Mahasiswa yang mengharapkan feedback akan mempengaruhi pencapaian tujuan pembelajaran dan emosi mahasiswa. ${ }^{37}$ Feedback juga sebaiknya mendetail dan spesifik ${ }^{1,20}$ dan dengan kadar yang dapat diterima mahasiswa. ${ }^{38}$

Selain aspek stuktural feedback, tutor juga harus memperhatikan aspek sosio-afektif. Tutor harus mampu memunculkan rasa keyakinan serta memunculkan komitmen serta kepercayaan diri mahasiswa dalam mencapai tujuan pembelajaran dan kedekatan adalah kunci utama. Tutor jangan memunculkan rasa ketakutan-ketakutan dan memberikan pengalaman tidak mengenakkan karena dapat mempengaruhi penerimaan feedback oleh mahasiswa. ${ }^{8,34,35,39,40}$ Agar kedekatan itu dapat terbentuk, tutor harus memperhatikan keinginan dan kebutuhan mahasiswa dalam memberi feedback. Feedback akan lebih efektif bila menyingung dengan tepat apa yang sebenarnya dibutuhkan dan diminati mahasiswa. ${ }^{41}$ Mendiskusikan feedback akan memungkinkan tutor untuk memahami dengan jelas keinginan mahasiswa dan mahasiswa juga akan lebih jelas memahami feedback tutor. ${ }^{30}$

Self-assessment adalah sebuah bagian penting dari feedback dan disebut sebagai bagian pertama dari pemberian feedback. ${ }^{11,12,36,38}$ Self-assessment adalah proses generalisasi dan reflektif untuk menghasilkan sebuah penilaian sumatif mengenai tingkat kemampuan seseorang yang dapat membantu mahasiswa merefleksikan apa yang mereka inginkan, apa yang mereka sudah pelajari, bagaimana mereka berubah dan apa pengalaman belajar yang menyokong perbaikan tersebut. ${ }^{27,41}$ Kesulitan yang sering dialami dalam memfasilitasi self-assessment ini adalah tutor yang tidak tahu kalau self-assessment merupakan bagian dari feedback dan mahasiswa yang cenderung untuk menilai lebih dirinya sendiri. ${ }^{27}$ Tutor harus memiliki kemampuan memfasilitasi proses ini. ${ }^{4}$ 
Untuk mengurangi dampak ketimpangan hubungan antara tutor dan mahasiswa maka tutor dapat memfasilitasi peer-feedback dalam tutorial. ${ }^{35,41}$ Peer feedback adalah komunikasi di antara mahasiswa dalam sebuah dialog yang dapat mempertajam pemahaman dan memperbaiki pembelajaran serta secara praktis lebih mudah diterima. Walaupun dalam pelaksanaannya, banyak kendala mulai dari ketidakmampuan menilai temannya dengan baik dan ketakutan akan malu karena kemungkinan kejelekan seseorang yang terpapar di depan mahasiswa lain. ${ }^{42}$

Pelatihan dapat memperbaiki kemampuan tutor dalam memberi feedback di dalam tutorial dan meningkatkan kepuasan mahasiswa terhadap kinerja tutor dalam memberi feedback. ${ }^{43,44}$ Sebuah sesi pelatihan sebaiknya diawali dengan brainstorming tutor mengenai pengalaman mereka dengan feedback untuk mendapat tilikan mengenai konsep pemahaman feedback yang mereka anut selama ini. Kemudian dilanjutkan dengan pemberian materi pemberian feedback yang baik dan dilanjutkan dengan role play dengan skenario kasus dengan standardized students. Pelatihan diakhiri dengan self-assessment dari para tutor dan menanyakan standardized students terhadap feedback yang mereka terima. ${ }^{45}$ Selain ke tutor, materi feedback dapat diberikan ke mahasiswa dan dapat meningkatkan kemampuan mahasiswa dalam memberi dan menerima feedback. ${ }^{21}$

\section{KESIMPULAN}

Pemberian feedback di Fakultas Kedokteran Universitas Islam Sumatera Utara belum memenuhi prinsip pemberian feedback yang efektif walaupun feedback, yang dipahami sebagai penilaian kualitatif terhadap performa mahasiswa, disepakati oleh mahasiswa dan tutor sebagai sesuatu yang penting dan memberikan manfat dalam proses belajar mahasiswa.

Dalam pemberian dan penerimaan feedback, tutor dan mahasiswa memegang pengaruh penting. Keduanya saling mempengaruhi agar feedback dapat memberi manfaat. Teknis pelaksanaan tutorial dan isi feedback itu sendiri juga turut berpengaruh.

Agar feedback dapat diterima dan dimanfaatkan dengan baik oleh mahasiswa dan dapat diberikan dengan baik oleh tutor, maka mahasiswa dan tutor memiliki preferensi terhadap pemberian feedback. Preferensi ini meliputi aspek struktural feedback hingga menginginkan adanya keterlibatan institusi sebagai penyelanggara tutorial dan pihak yang melatih tutor dalam kegiatan tutorial.

\section{SARAN}

Hasil penelitian ini diharapkan dapat digunakan sebgaai bahan pertimbangan untuk pengembangan kualitas tutor terutama kemampuan tutor dalam memberikan feedback di tutorial karena penelitian berusaha untuk menggambarkan pemberian feedback di tutorial yang selama ini dialami mahasiswa.

Keterbatasan penelitian ini adalah tidak mengikutsertakan observasi sebagai salah satu metode penelitian. Untuk penelitian berikutnya, penulis menyarankan agar penelitian selanjutnya melibatkan observasi sehingga didapati gambaran langsung pemberian feedback oleh tutor. Penelitian ini juga menunjukkan bahwa aspek sturuktural feedback masih belum dijalankan sesuai dengan prinsip pemberian feedback. penulis juga menyarankan agar penelitian berikutnya berfokus pada aspek struktural feedback dan efeknya terhadap penerimaan feedback oleh mahasiswa.

\section{UCAPAN TERIMA KASIH}

Terima kasih yang sebesar-besarnya kepada dr. Widyandana, MHPE., PhD dan dr.Yoyo Suhoyo, M.Med.Ed. atas bimbingan dan masukannya selama penulisan naskah publikasi ini.

\section{DAFTAR PUSTAKA}

1. Ende J. Feedback in medical education. JAMA 1983; 250(6); 777-81.

2. Brodksy WT, Doherty EG. Providing effective feedback. NeoReviews 2010; 11(3): 117-22.

3. Hamid Y, Mahmood S. Understanding constructive feedback: a commitment between teachers and students for academic and professional development. J Pak Med Assoc 2010; 60(3): 224-7.

4. Branch WT, Paranjape A. Feedback \& reflection: teaching methods for clinical teaching. Academic Medicine 2002; 77(12): 1185-8. 
5. Murphy C, Cornell J. Student perception of feedback: seeking a coherent flow. Practitioner Research in Higher Education 2010; 4(1): 41-51.

6. Rowe AD, Wood LN. Student perception and preferences for feedback. Asian Social Sciences 2008; 4(3): 78-88.

7. Nicol DJ, Macfarlene-Dick D. Formative assessment and self-regulated learning: A model and seven principles of good feedback practice. Studies in Higher Education 2006; 31(2): 199-218.

8. Hattie J, Timperley H. The power of feedback. Review of Educational Research 2007); 77(1): 81-112.

9. Kaprielian VS, Gradison M. Effective use of feedback. Fam Med 1998; 30(6): 406-7.

10. Miser WF. Giving effective feedback. [Online] 2006 [cited 2010 Apr 26]. Available from URL : http:// www.ohioafp.org/pdfs/member/educatorresources/ GivingEffectiveFeedback.pdf

11. Carr S. The foundation programme assessment tools: an opportunity to enhance feedback \& trainers. Postgrad Med 2006; 82: 576-9.

12. Chowdurry RR, Kalu G. Learning to give feedback in medical education. Obstetrician \& Gynaecologist 2004; 6: 243-7.

13. Harsono. Pengantar problem-based learning. Yogyakarta: Medika FK UGM; 2008.

14. Walsh A. The Tutor in PBL; a novice's guide. Canada: Program for Faculty Development.McMaster University, Faculty of Health Sciences; 2005.

15. Azer S. Navigating Problem-based learning. Australia: Elsevier; 2008.

16. Naylor R, Baik C, Asmar C, Watty K. Good feedback practice. [Online] 2014 [cited 2015 Apr 18]. Availble from URL : http://ww.cshe.unimelb.edu.au

17. Bing-You RG, Trowbridge RL. Why medical educators may be failed at feedback. JAMA 2009; 301(12): 1330-1.

18. Boehler ML, Roger DA, Schwind CJ, Mayforth R, Qui n J, Williams RG, Dunnington G. An investugarion of medicl students reaction to feedback: A randomized controlled trial. Medical Education 2006; 40: 746-9.

19. Duncan N. Feed-forward: improving students' use of tutors' comments. Assessment \& Evaluation in Higher Education 2007; 32(3): 271-83.

20. Hesketh EA, Laidlaw JM. 1: Feedback. Medical Teacher 2002; 245-8.
21. Kruidering-Hall M, O'Sullivan PS, Chou CL. Teaching feedback to first year medicl students: long term skill retention and accuracy of student selfassessment. J Gen Intern Med 2009; 24(6): 721-6.

22. Patton. Qualitative evaliuation and research method. $2^{\text {nd }}$ ed. London: SAGE Publication; 1990.

23. Moore GF, Audrey S, Barker M, Bond L, Bonell C, Hardeman W, Moore L, O'cathain A, Tinati T, Wight D, Baird J. Process evaluation of complex intervention: medical research council guidance. The BMJ 2015; 350:1528.

24. Johnson B, Christian L. Educational research: Quantitaive, qualitative and mixed approaches. $4^{\text {th }}$ ed. USA: SAGE; 2011.

25. Butler DL, Winne PH. Feedback and self-regulated elarning: a theoretical synthesis. Review of Educational Research 1995: 65(3): 245-81.

26. Scarparo S, Gracia L. Conceptualising feedbackmapping the student experience as a first stage of feedback development. [Online] 2011 [cited 2015 Dec 1]. Available from URL : http://www.warwick. ac.uk/fac/cross.fac/iatl/funding/fundedprojects/ fellowships/scarparo_and_gracia_interim_report. pdf

27. Eva KW, Regehr G. "I'll never play professional football" and other fallacies of self-assessment. Journal of Continuing Education in the Health Proffession 2008; 28(1): 14-9.

28. Algiraigri AH. Ten tips for receiving feedback effectively in clinical practice. Med Educ Online 2014;19.

29. Orsmond P, Merry S, Reiling K. The student use of formative feedback. [Online] 2002 [cited 2015 Dec 1]. Available from URL : http://www.leeds.ac.uk/ educol/documents/00002233.htm

30. Amin Z, Khoo HE. Basic in Medical Education. Singapore: World Scientific; 2009.

31. De Grave WS, Dolmans DHJM, Van der Vleuten CPM. Profiles of effective tutor in problem-based learning, scaffolding student learning. Medical Education 1999; 33: 901-6.

32. Oliffe J. Facilitation in problem-based learningespoused theory versus theory in use: reflections of a first time user. Australian Electronic Journal of Nursing Education 2000; 5(2).

33. Harden RM, Crosby J. AMEE guide no 20: the good teacher is mpre than a lecturer-the twelve roles of the teacher. Medical Teacher 2000; 22(4): 334-47. 
34. Price M, Handley K, Millar J. Feeback: focusing attention on engagement. Studies in Higher Education 2011; 36(8): 879-96.

35. Yang M, Carless D. The feedback triangle and the enhancement of dialogic feedback process. Teaching in Higher Education 2013; 18(3): 285-97.

36. Hewson MG, Little ML. Giving feedback in medical education: verification of recommended technique. J Gen Intern Med 1998; 13: 111-6.

37. Pekrun R, Cusack A, Murayama K, Elliot AJ, Thomas $K$. The power of anticipated feedback: effects on students' achievement goals and achievement emotion. Learning and Instructions 2010; 29: 115. 24.

38. Brookhart SM. How to give effective feedback to your students. USA: Association for Supervision and Curriculum Develoment; 2008.

39. Eva KW, Armson H, Holmboe E, Lockyer J, Loney E, Mann K, Sargeant J. Factors influencing responsiveness to feedback: on the interplay between fear, confidence, and reasoning processes. Adv in Health Sci Educ 2012; 17: 15-26.
40. Chung YB, Yuen M. The role of feedback in enhancing students' self-regulation in inviting school. Journal of Invitational Theory and Practise 2011; 17: 22-7.

41. Carless D, Salter D, Yang M, lam J. Developing sustainable feedback practice. Studies in Higher Education 2010; 1: 1-13.

42. Liu N-F, Carless D. Peer-feedback: the learning element of peer assessment. J Gen Intern Med 2006; 11(3): 279-90.

43. Farmer EA. Faculty development for problem-based learning. Eur J Denr Educ2004; 8: 59-66.

44. Baroffio A, Nendaz MR, Perrier A, Vu NV. Tutor training, evaluation criteria and teaching environment influence students' ratimgs of tutor feedback in problem-based learning. Advances in Health Sciences Education (2007); 12: 427-39.

45. Brukner H, Atlkorn DL, Cook S, Quinn MT, McNabb WL. Giving effective feedback to medical students: a workshop for faculty and house staff. Medical Teacher 1999; 21(2):161-5. 